\title{
Educação física, slackline e o cotidiano de uma escola pública
}

\section{Physical education and slackline use in environmental education: the daily life of a public school}

\author{
${ }^{1}$ Marcelo Paraiso Alves marcelo.alves@ifrj.edu.br \\ ${ }^{2}$ Cassio Martins \\ ${ }^{2}$ Gustavo Alves Vinand Kozlowski Farias \\ ${ }^{3}$ Dimitri Wuo Pereira \\ ${ }^{1}$ Christiane Guimaraes Pancardes Silva
}

\section{RESUMO}

Objetivo: Investigar o processo de ensino e aprendizagem de slackline no contexto escolar de uma instituição pública. Método: Participaram da pesquisa 33 discentes do Curso Técnico em Automação Industrial. Como procedimento de produção de dados, utilizamos o diário de bordo e entrevistas acerca da questão pesquisada. Os resultados apontam a possibilidade do uso do slackline ampliando as possibilidades de participação dos discentes em aula, bem como a relação do esporte com as questões socioambientais. A tematização da aula via Educação Ambiental representa um caminho para (re)significar as aulas de Educação Física no Ensino Médio.

Palavras-chave: Esportes. Escola. Educação Ambiental.

\begin{abstract}
Objective: This study investigates the teaching and learning process of slackline in the context of a government school. Method: The participants were 33 students of the Technical Course in Industrial Automation. As data production procedure, we used the logbook and interviews on the research question. Results: The results show the possibility of slackline use expanding the possibilities of participation of students, and the relationship with social and environmental issues. Using Environmental Education as theme represents a path to (re) signify Physical Education classes in high school.
\end{abstract}

Keywords: Sports. School. Environmental Education. 


\section{INTRODUÇÃO}

Deparamo-nos nas últimas décadas com uma concepção de Educação Física escolar que busca a referência no esporte, tornando-se um produto a ser consumido, mesmo que iconograficamente, por um grande público, inclusive no âmbito escolar. No entanto, Rodrigues e Darido (2006) mencionam que na atualidade, as abordagens sócio-culturais da Educação Física vêm tecendo críticas em relação ao papel educativo do esporte, alertando para o seu caráter reprodutivista e conservador.

Nesta linha de pensamento, Sanches Neto et al.(2013) criticam o processo de ensino e aprendizagem que se estabelece única e exclusivamente a partir de abordagens biológicas e psicológicas, pois desconsideram questões relevantes para o processo de construção do conhecimento, como por exemplo, os aspectos econômicos, sociais, políticos, dentre outros.

Considerando que a escola não é clube e nem centro de treinamento desportivo Vago (2009) assinala que não é a função da educação física, restringir o ensino a simples execução de gestos eficientes e mecanicamente perfeitos para se atingir uma determinada performance contemplando alguns esportes tradicionais (vôlei, basquete, handebol e futsal), mas, a de favorecer a circulação da diversas culturas corporais de movimento.

Franco et al. (2014), seguindo esta ótica reiteram que crianças, adolescentes e jovens possuem o direito a outras experiências, ampliando os conhecimentos e possibilidades corporais. Os autores ainda ressaltam a necessidade de incluir outros conteúdos na escola, como por exemplo: Skate, Parkour, Surfe, Trekking e ainda o Slackline, cultura corporal central deste estudo.

Neste sentido cabe questionar: Quais as contribuições do Slackline para a educação física escolar? O Slackline permite a abordagem das questões socioambientais?

Guimarães et al. (2007, p. 158) mencionam que apesar do referido cenário, na qual a disciplina citada buscou sua centralidade no esporte de competição, a educação física escolar, nas últimas décadas, discute novas propostas teóricas, por intermédio de novos procedimentos pedagógicos, na tentativa de superar uma prática "acrítica, tecnicista e elitista. Calcada, por sua vez, em um rendimento padrão retirado da performance esportiva, para uma educação em que temas relevantes sejam tratados de modo conjunto”, contrariamente a perspectiva dicotômica que hegemonicamente se apresenta na educação básica.

Outro aspecto a se observar, emerge da motivação para as aulas de Educação Física. Souza Júnior e Darido (2009) fazem referência ao alto número de alunos dispensados das aulas, o que nos faz notar que este fenômeno não é um fato isolado. Sobre isso, Dudley et al.(2012) ao pesquisar adolescentes australianos enfatizam que o nível de prática de atividade física é baixo. Os autores ainda ressaltam que em alunos orientais e asiáticos o percentual de alunos envolvidos com a prática de atividade física é ainda menor.

Não é intenção deste estudo negar as contribuições das práticas desportivas supracitadas, pois como Kanters et al. (2012) reconhecemos a importância que os esportes de quadra desempenham tanto no espaço escolar, quanto para além de seus muros, porém o que pretendemos é apresentar a potencialidade do slackline, mais especificamente o Trickline, como ação educativa possível de ser praticada em âmbito escolar.

O Trickline é uma vertente do Slackline que utiliza manobras estáticas e dinâmicas. Para Mendes, Gomes e Bello (2015, p. 9) "tais manobras incluem ações aéreas, por meio de saltos, giros, quedas sobre a fita com diferentes partes do corpo, sentada, lateralmente, o que desafia muito o equilíbrio do praticante”. Os autores ainda mencionam que as fitas possuem elasticidade e são colocadas a uma altura de aproximadamente 60 centímetros do solo. 
A escolha pelo slackline deve-se também pela perspectiva enunciada por Rodrigues e Darido (2006, p.1), já que a possibilidade de discutir a constituição histórica e estrutural nos quais os sujeitos se apropriam dos espaços públicos de lazer. E ademais, buscam alternativas que assegurem condições mínimas de participação, adequação e "ampliação da oferta dos espaços por parte dos órgãos públicos caracterizam-se como uma ação pedagógica significativa”.

Cabe ressaltar que o presente estudo emerge de uma pesquisa mais ampla que pretendeu investigar o processo de ensino e aprendizagem nas aulas de Educação Física desenvolvidas no Instituto Federal do Rio de Janeiro campus Volta Redonda (IFRJ-CVR) e, sua relação com a Educação Ambiental, propondo a elaboração de um material didático em formato de DVD.

\section{METODOLOGIA}

O presente estudo teve uma abordagem de natureza qualitativa, pois para Gil (2008, p. 175) “ao contrário do que ocorre nas pesquisas experimentais e levantamentos em que os procedimentos analíticos podem ser definidos previamente, não há fórmulas ou receitas predefinidas para orientar os pesquisadores”. O autor ainda menciona que a análise dos dados na pesquisa qualitativa depende da capacidade do pesquisador.

Assim, cabe frisar que, participaram da pesquisa 33 estudantes do $4^{\circ}$ período do Curso Técnico de Nível Médio em Automação Industrial do IFRJ - CVR. Os estudantes possuíam no período da pesquisa, idade compreendida entre 15 e 17 anos. Ressaltamos que em detrimento da idade dos participantes os responsáveis e os participantes assinaram o Termo de Consentimento Livre e Esclarecido, visto que o estudo foi aprovado pelo Comitê de Ética em Pesquisa do UNIFOA, sob parecer número 21495013.8.0000.5237.

Para a produção de dados utilizamos o diário de bordo, na perspectiva mencionada por Zabalza (2004), na intenção de apreender os contextos: físico, social, e cultural em que ocorreram os fatos narrados. As observações e anotações no diário de bordo ocorreram na perspectiva da pesquisa com o cotidiano, conforme preconiza Ferraço (2007). Estávamos imersos como docentes no processo de ensino e aprendizagem, pois, as observações ocorriam durante o período das nossas aulas (terças-feiras de $8 \mathrm{~h} 50$ as 10h20).

Outro instrumento utilizado na produção de dados foi a entrevista com perguntas semiestruturadas, contendo as seguintes questões: a) Você já havia praticado o slackline as aulas de Educação Física? b) Qual a diferença entre as aulas desenvolvidas com os esportes tradicionais e com o Esporte de Ação? c) Quais os cuidados que se deve ter com o meio ambiente ao praticar o slackline?

Considerando a necessidade de apreender as impressões dos alunos sobre o processo de ensino e aprendizagem do slackline, utilizamos na realização das entrevistas e para captação do áudio um microfone de lapela acoplado a um notebook Inspiron 15 série 5000.

\section{1 Percurso Metodológico}

O método utilizado para mergulharmos nos dados apreendidos na pesquisa (narrativas e práticas cotidianas) se aproxima do Paradigma Indiciário de Ginzburg (1989). Tal paradigma nos permitiu buscar sinais e pistas dos conhecimentos produzidos nos processos de ensino e aprendizagem dos slackline. Para o autor, o paradigma Venatório - relativo à caça e ao seu universo - e o Divinatório - relativo à adivinhação ou aos instrumentos dessa prática, permitem acessar fatos aparentemente insignificantes (pistas, indícios).

Assim, fundados nesta perspectiva, partimos do pressuposto de que o homem ao nascer em uma cultura enredada de caçadores e, tendo sido o primeiro a 'narrar uma história', porque era a forma de transmitir uma sé- 
rie coerente de eventos ocorridos, desenvolveu a habilidade de ler, nas pistas "mudas” o percurso percorrido pela caça. 'Decifrar’ ou ler’ as pistas dos animais são metáforas. Dessa forma, o saber venatório consiste em passar de fatos aparentemente insignificantes (pistas, indícios) para a realidade complexa, não observável diretamente.

Nesta linha de pensamento, Ginzburg (1989) apontando dissensões entre dois modos de ler e compreender uma determinada 'realidade' revela a atitude, o esforço intelectual e rigoroso em ambos os casos, sendo por ele considerada muito próxima: análises, comparações e classificações formalmente idênticas.

Dessa forma, o método nos permitiu "caçar" indícios que visibilizam os processos de ensino e aprendizagem do slackline e seu enredamento a uma possível Educação socioambiental no cotidiano das aulas no IFRJ-CVR.

É importante ressaltar que a discussão dos dados se desenvolveu por intermédio dos autores utilizados na revisão da literatura ora apresentada.

\section{2 Procedimentos}

O slackline, neste estudo, é concebido como linguagem que supera a perspectiva meramente motriz, permitindo ressignificar valores, intencionalidade, sentidos, contribuindo para o desenvolvimento de um processo de ensino e aprendizagem articulados ao contexto social. Portanto, ao conceber o cotidiano escolar como um espaço de culturas, fundados na ótica de Certeau (1994) buscamos também configurar os seus praticantes, sejam eles de qualquer faixa etária como produtores, reinventores do consumo que lhes chega.

Considerando o exposto e sabendo que a LDB/96 propõe que a temática da Educação Ambiental transversalize os conteúdos ministrados na Educação Básica, propomos aos estudantes envolvidos na pesquisa a ruptura com os esportes tradicionais. Partimos do pressuposto de que a referida cultura corporal precisava ter um sentido/significado para que os alunos pudessem estabelecer uma conexão com as questões socioculturais.

Assim, enredar a Educação Ambiental ao Slackline foi uma tentativa de visibilizar uma questão local, que emerge no cotidiano da cidade e que impacta os praticantes de Slackline: a prefeitura do município proibiu a colocação das amarras nas árvores. Portanto, foi possível discutir questões de cidadania perpassando pelos direitos e deveres tanto do poder público, quanto do sujeito ordinário que reinventa os espaços que habita.

Nesta linha de pensamento, o currículo se constituiu em um espaço de disputas, permitindo que o debate e a tensão promovendo a imersão de potencialidades, acolhendo e dando o tratamento cuidadoso às diversas culturas em circulação.

É importante que se perceba que a concepção de Educação Ambiental no estudo, não se vinculou a perspectiva ecológica, mas por meio de uma abordagem que se sustenta a partir de três dimensões: a dimensão ética (a solidariedade), a dimensão política (a participação) e a dimensão estética (o reencantamento), conforme explicitado por Tristão(2005).

Com relação à dimensão ética, torna-se perceber que o meio ambiente se inscreve a partir de uma complexidade de interseções e dimensões, sendo a solidariedade um forte componente ético e político para a promoção de práticas cotidianas significativas, no que se refere à sensibilidade solidária. Neste sentido, a autora menciona a imperativa necessidade do desenvolvimento do respeito pelo outro e, convida-nos a entender esta conduta como aquela que vai "respeitar o outro como legítimo outro na convivência, seja ele um ser humano, seja um grupo social, seja a natureza” (TRISTÃO, 2005, p. 257). 
No que diz respeito à dimensão política, buscamos em Santos (2011)' a ênfase na solidariedade, pois esta converte a comunidade no campo privilegiado do conhecimento emancipatório, nesse caso "trata-se de um hic et nunc, local e imediato, que pode englobar o planeta e o mais distante futuro” (p. 81).

Assim, fundado nas ideias de Tristão (2005), não estamos propondo aqui o uso da noção de participação fundada nas ideias de objetividade, quantidade e coletividade, conforme proposto até a década de 1980, mas a aproximação à racionalidade estético-expressiva que, por sua origem aberta, é flexível e inacabada como qualquer obra de arte, a própria natureza, ou alguns domínios da vida social.

Para Santos (2011, p. 76) a racionalidade estético-expressiva se constitui a partir de três dimensões que priorizam a dinamicidade ao contrário da fixidez: o prazer, a autoria e a artefactualidade discursiva. Para o autor, o prazer está além do alcance da regulação não podendo ser enclausurado: "Foi no campo da racionalidade estético-expressiva que o prazer, apesar de semienclausurado, se pode imaginar utopicamente mais do que semiliberto".

Nesta perspectiva Oliveira (2012, p. 7) salienta que a noção de autoria também busca a ruptura com a regulação e o controle, visto que nos permitir "devolver aos sujeitos a responsabilidade sobre suas vidas e destinos, a autoria do mundo social que, se é quem os tece, é também tecido por eles”. Nesta linha de ação, a autora atua seguindo em direção ao meio artístico e literário, significando a existência de aberturas para que o sujeito se torne criador, seu desafio é a busca constante da autonomia na sua produção.

Por fim, a artefactualidade discursiva, que é concebida como uma produção intencional e um ato construtivo. No entanto, esta noção se configura por intermédio de um discurso argumentativo e retórico que busca persuadir pela argumentação. O principal aspecto a ser considerado é o debate em torno da percepção da realidade que se configura a partir de outras visões de mundo.

Assim, se a noção de solidariedade passa pela dimensão ética, pelo respeito ao "outro", sendo este um sujeito, um grupo social ou a natureza; a noção de participação aqui proposta é a que se constitui a partir da fabricação singular e autônoma dos sujeitos, respeitando as possibilidades, interesses, anseios e demandas nos projetos propostos pela escola.

Logo, ao decidir com os alunos a cultura corporal de movimento que iria compor o conteúdo de ensino e aprendizagem do bimestre, consideramos a noção de participação explicitada, já que buscávamos coletivamente, a construção singular do grupo. Dessa forma, decidimos coletivamente pelo slackline.

Dessa forma, considerando a decisão do grupo, passamos a desenvolver metodologicamente as aulas em três fases. A primeira, em que os conteúdos e objetivos da aula eram discutidos com os alunos. Segunda, que tomava o maior tempo disponível: a produção dos conhecimentos. E, por fim, a terceira fase, na qual se discutiam as considerações e avaliávamos o realizado, levantando perspectivas para as próximas aulas.

\section{EDUCAÇÃO FÍSICA E SLACKLINE: POSSÍVEIS AÇÕES EDUCATIVAS}

Com o intuito de melhor explicitar o movimento estabelecido nas aulas do IFRJ-CVR, apresentaremos as oito aulas que fizeram parte do estudo: A primeira aula buscou contextualizar o slackline como uma cultura corporal de movimento, visto como processo histórico do referido esporte, suas vertentes (trickline, longline, waterline, highline) e por fim, a justificativa de articulação do esporte com os problemas socioambientais.

No primeiro momento procuramos esclarecer aos estudantes, que a unidade de ensino - slackline - seria mediada pela temática socioambiental. Apresentamos vídeos e fotografias que visibilizavam os erros cometidos 
prejudicando árvores e causando risco socioambiental para os praticantes e espectadores. Ao término da aula foi disponibilizado tempo para avaliação, debates e perguntas, sendo possível introduzir os problemas de montagens do equipamento.

Na segunda aula, revisamos o conteúdo da aula anterior eximindo possíveis dúvidas e apresentamos o objetivo da aula. Na intenção de problematizar as questões socioambientais, decidimos apresentar os equipamentos para a montagem do slackline: sistema primitivo e sistema com catraca, bem como os erros na montagem, riscos e consequências.

Portanto, conceituamos os sistemas de montagem, suas funções e por intermédio de fotos, vídeos e com a presença dos equipamentos ensinamos como montar e desmontar o slackline. Ao final da aula disponibilizamos um tempo para perguntas e debates (avaliação). O depoimento dos estudantes revela o conhecimento criado nas aulas:

J: Ter certeza que a fita está presa em local seguro, usar materiais de boa qualidade, proteger as árvores com protetor para não machucá-la com o atrito da fita.

B: A fita precisa estar em bom estado, o local deve ser forte o suficiente pra aguentar a tração da fita e é imprescindível o uso do protetor, para proteger tanto a fita quanto o local onde ela é amarrada.

E: O principal cuidado que se deve ter é com a natureza, usar protetores nas árvores é importantíssimo. O outro cuidado que se deve ter é com a segurança do equipamento e das pessoas que vão andar sobre a corda $(. .$.$) .$

\section{P: Em relação à natureza, é necessário pôr proteção nas árvores (grifos do autor)}

É relevante salientar a preocupação dos estudantes com o impacto socioambiental, pois antes de iniciar a prática da referida modalidade precisam proteger o local em que o equipamento será fixado. No entanto, um detalhe na fala do aluno $\mathbf{B}$ e do aluno $\mathbf{E}$ emergem como sinais do tratamento pedagógico mencionado: proteger as árvores e as pessoas que praticam o slackline. Esse indício, conforme menciona Ginzburg (1989) revela a preocupação com a sua segurança e a segurança das pessoas envolvidas, princípio ético e político: solidariedade (educação socioambiental).

Outro aspecto que nos chamou a atenção foi a construção do conhecimento desenvolvida no transcorrer das aulas. Com relação ao referido aspecto, Betti e Zuliani(2002, p. 75) citam que "a dimensão cognitiva far-se-á sempre sobre esse substrato corporal”.

O depoimento a seguir revela indícios do processo de construção de saber dos alunos:

A.P: Deve-se observar a estrutura da árvore onde o slack vai ser montado, para ver se ela aguentaria ou não. Quando for instalar o equipamento, é de extrema importância usar uma proteção, para que o xilema da árvore não seja agredido pela tensão do slack e por consequência, não mate a árvore.

Percebemos na narrativa o estudante se reporta a proteção da árvore ao aludir que: “o xilema4 da árvore não seja agredido”. É importante frisar que o conceito de xilema não foi tratado nas aulas de Educação Física. No momento em que o estudante busca a sua referência em conteúdos ministrados em outras disciplinas explicita uma fabricação própria, um modo de consumir e usar singularmente tudo aquilo que lhe chega.

4 Em Botânica denomina-se xilema o tecido das plantas. Nas árvores o xilema secundário é o constituinte da madeira, local onde se fixa o equipamento do slackline. 
Na terceira aula, iniciamos o processo educativo buscando a ludicidade e o prazer como centralidade na pratica do slackline. A primeira atividade se desenvolveu com uma brincadeira de equilíbrio e reconhecimento das diversas linhas da quadra e, posteriormente, com um pique que utilizava as linhas demarcatórias. O pique linha, ‘denominação dos próprios estudantes', consistia em se deslocar sob a demarcação da quadra fugindo de um pegador.

A segunda atividade ocorreu em duplas ou em trios na qual os estudantes praticaram o slackline. As fitas foram colocadas a uma altura aproximada de $30 \mathrm{~cm}$ do solo, na intenção de possibilitar maior segurança aos alunos. A atividade em dupla tinha como intuito possibilitar a segurança do aluno que estava sob a fita. Antes de iniciarmos as atividades procuramos explicar os riscos de brincadeiras e atitudes inadequadas no decorrer delas, utilizamos como referência o princípio ético do respeito ao companheiro que estaria executando a ação de equilíbrio na fita e o risco de acidentes.

É relevante salientar que a segurança foi efetuada apenas com o apoio do colega utilizando uma das mãos, não devendo prender ou segurá-lo pelo braço ou qualquer parte do corpo do praticante. Para Darido e Tahara (2016), o esporte de aventura pode oferecer novos e significativos desafios para as aulas de educação física.

Assim, é relevante salientar que a intenção do uso deste tipo de segurança foi permitir ao estudante que estava sob a fita, o desenvolvimento da habilidade do equilíbrio, superando ou enfrentando o receio da queda. Simultaneamente desenvolver técnicas corporais que permitiriam a sua saída da fita sem riscos de acidentes. Em contrapartida, o educando que oferecia o auxilio desenvolveria valores como: solidariedade, respeito aos limites individuais, cooperação, dentre outros.

As narrativas apresentam indícios do processo de ensino e aprendizagem dos estudantes por intermédio do slackline:

P.C: slackline é, obviamente, um esporte diferente dos que são lecionados geralmente nas escolas, como Futebol, Vôlei etc. Só que eu acho principalmente que a diferença está no desafio, na preparação do equilíbrio (...).

P.B: No início tive um pouco de dificuldade, mas à medida que ia melhorando, meu interesse aumentava, o que tornou a experiência bem agradável.

R: Foi bem interessante, pois nas primeiras vezes em que eu subi na fita, não conseguia ficar nem 5 segundos parada e ao final do bimestre eu consegui andar toda a fita (e isso para mim foi muito prazeroso).

O objetivo do trabalho em grupo foi estabelecer momentos de conversação que auxiliassem os alunos em suas descobertas. González Rey (2004, p. 126) menciona o sistema de conversação com o intuito de pesquisa científica, no entanto, buscamos essa metodologia como uma maneira de conduzir o grupo "a campos significativos de sua experiência pessoal (...). A partir desses espaços, o relato expressa seu mundo, suas necessidades, seus conflitos, suas reflexões”. Ao problematizar a dificuldade de equilíbrio permitíamos aos estudantes um espaço de diálogo e troca de experiências.

Entretanto, outra noção de conversação que também nos influenciou para que pensássemos no trabalho em grupo e na construção de conhecimentos em redes, emerge de Maturana(2001, p. 132): as conversações são "as diferentes redes de coordenações entrelaçadas e consensuais de linguajar e emocionar que geramos ao vivermos juntos como seres humanos”. 
Pensando na ótica do autor, a proposta de trabalhar em grupo para debater as dificuldades e as experiências partia do princípio de que ao entender que cada estudante na sua singularidade carrega as marcas da cultura, da sociedade, e das vivências que o forjou. O depoimento de um aluno nos é revelador ao mencionar que romper com a prática do esporte tradicional permitiu fugir dos padrões:

G: O slackline eu acho que te proporciona uma liberdade maior pra você desenvolver suas habilidades dentro do esporte, não tendo que seguir um padrão único sempre, te dando mais liberdade e mais prazer quando praticado (DIÁRIO DE BORDO - 07/11/2013).

Na parte final da aula foi realizada a avaliação, por intermédio de conversas sobre as ações realizadas durante a aula. Os alunos puderam falar dos medos, das dificuldades, retirar dúvidas e relatar a superação das etapas no decorrer do processo de ensino e aprendizagem.

Na quarta aula, após a construção de conhecimento mencionada, os(as) alunos(as) foram desafiados(as) a superar os seus limites individuais.

A intenção era permitir o desenvolvimento da percepção corporal, o equilíbrio e a dinâmica do movimento sob a fita. Para tal ação, buscamos variações de altura e distância, possibilitando diferentes níveis de aprendizado, a fim de atender as demandas singulares, sabendo que a progressão de cada um surge das experiências de vida e da relação que estabelece com sua corporeidade.

Considerando tal noção - corporeidade - o educando possuía autonomia biomecânica para interferir e adaptar ao seu movimento os quatro princípios ensinados (pés direcionado a frente, joelhos semiflexionados, braços acima da linha dos ombros e olhando para um ponto fixo a frente) a fim de manter-se equilibrado sob a fita.

Na quinta aula, percebendo o desenvolvimento das habilidades e do interesse dos educandos pela prática do slackline, enfatizamos a temática socioambiental, relembramos os riscos e acidentes que podem ser provocados durante a montagem: colocação inadequada do equipamento, checagem da montagem antes de usá-lo, preocupação com a distância dos espectadores, check list dos pontos de montagem, cuidado com a manutenção e durabilidade das fitas e equipamentos, dentre outros.

A atividade se desenvolveu a partir da divisão da turma em grupos, cabendo a cada equipe a ação de montar e desmontar o equipamento seguindo as normas de segurança aprendida nas aulas anteriores. No final da aula os alunos relacionaram os conteúdos adquiridos nas aulas com a prática e o manuseio para a montagem dos sistemas.

Na sexta aula, considerando os conteúdos desenvolvidos nas aulas anteriores e com a preocupação da temática anunciada - socioambiental - promovemos uma aula para além dos muros da escola. A intenção foi proporcionar aos educandos a prática do slackline em um espaço urbano e tivessem a oportunidade de montar os sistemas, utilizando árvores como ponto de ancoragem. Os estudantes foram levados para uma praça onde puderam vivenciar os cuidados com as árvores, utilizando os conhecimentos adquiridos para a montagem dos equipamentos, os excertos da pesquisa revelam pistas das vivências dos alunos:

J: A visita técnica me agregou muito mais experiência e segurança na hora de montar os equipamentos ao ar livre e na natureza.

P: As práticas foram também muito boas, porque saímos do ambiente colegial para praticar slackline em outros lugares, num lugar com mais contato com a natureza. 
A: Gostei, pois assim foi possível realizar na prática tudo aquilo que aprendemos na teoria.

Praticar a referida modalidade esportiva em um local fora da escola possibilitou que os(as) educando(as) utilizassem o slackline como uma opção de lazer, tendo como centralidade o caráter lúdico e a promoção da saúde.

Outro aspecto relevante abordado nesta atividade foi o impacto ambiental causado pelo esporte de aventura. Para Maroun e Vieira ${ }^{28}$, a referida prática esportiva se relaciona com espaços privilegiados pela natureza, pois são caracterizadas pela interação de seus praticantes com o ambiente citado. Se por um lado este aspecto favorece a aproximação do ser humano a natureza, por outro lado, com o aumento do número de praticantes pode acarretar um impacto significativo em tal espaço. Assim, buscamos problematizar com os estudantes a responsabilidade dos esportistas que buscam na prática mencionada uma forma de lazer ou promoção da saúde.

Marinho e Inácio (2007, p. 56) caminham nesta perspectiva ao mencionar que a intervenção "antrópica pode ser nociva ou benéfica, dependendo de variáveis espaciais, temporais, culturais, religiosas e econômicas. Por isso, discutir a relação entre natureza e educação física, mediada pelas atividades de aventura mostra-se tão importante”.

No intuito de problematizar os ensinamentos proporcionados no processo teleológico apresentado ao longo das aulas anteriores; sabendo que a avaliação se desenvolve processualmente, por que resguarda os aprendizados singulares dos sujeitos envolvidos nas etapas de construção do conhecimento. Procuramos na sétima aula outro espaço em que os estudantes pudessem vivenciar a colocação das amarras e dos equipamentos do slackline nas árvores, na intenção de aproximá-los do ambiente da referida modalidade praticada. Assim, realizamos uma visita técnica ao SESC de Barra Mansa-RJ que oferece um espaço com diversas árvores, local favorável à prática do slackline.

As tarefas solicitadas aos alunos consistiram em trabalhar em grupo durante as atividades de montagem dos dois tipos de sistemas (primitivo e catraca). Também solicitamos aos alunos a prática do esporte e da segurança do slackline.

Para finalizar, gostaríamos de ressaltar que apresentar o caminho percorrido pelos sujeitos da pesquisa nas atividades desenvolvidas no cotidiano das aulas do IFRJ em Volta Redonda, se deu na intenção de visibilizar o afastamento de atitudes individualistas que permeiam o esporte moderno. $\mathrm{O}$ adentrar outros espaços para além das quadras poliesportivas propiciou a estes sujeitos o contato com outros ambientes, mediante outras relações humanas: solidariedade, cooperação, trabalho coletivo, dentre outras. Cabe ainda ressaltar que tais práticas educativas estiveram mergulhadas em vivências estéticas que levaram os praticantes ao diálogo com as questões socioambientais, permitem perceber as possibilidades de reapropriação dos espaços públicos para práticas de esporte e lazer.

\section{CONSIDERAÇÕES FINAIS}

Consideramos, a partir do objetivo do estudo, que as fabricações cotidianas dos estudantes do IFRJ-CVR produziram um currículo peculiar a partir das práticas corporais que emergiram do contexto sociocultural em que os praticantes estavam imersos.

Neste sentido cabe frisar que as produções explicitadas neste trabalho não possuem a intenção de tornar-se um padrão ou modelo a ser seguido, mas de se colocar em um movimento contra-hegêmonico que concebe os esportes tradicionais como uma única possibilidade para a Educação Física da escola. Da mesma forma, é importante que se perceba que, os dados e a discussão realizada não possuem a pretensão de se tornar uma ver- 
dade única, pois percebemos que a referida produção coletiva (docentes e discentes) foi possível para o referido espaço e tempo em que foi produzida, por isso encarna a perspectiva singular preconizada pelos currículos criados cotidianamente.

Consideramos também que o processo de ensino aprendizagem se estabeleceu coletivamente, respeitando as variadas possibilidades diante do movimento dos alunos e professores envolvidos. É importante que se perceba que a centralidade da proposta está na maneira como os praticantes constroem o conhecimento enredando os conteúdos oriundos das práticas corporais (Educação Física) e a relação com os princípios que circundam a noção de educação socioambiental preconizada como temática a ser problematizada processualmente durante as aulas.

Sabemos que os Esportes de Aventura são modalidades praticadas em ambientes que extrapolam os muros da escola, no entanto, se reinventados diversificam o currículo da Educação Física, contribuindo como elemento potencializador favorecendo a discussão de temáticas que circundam os modos de vidas da sociedade atual.

Para finalizar, gostaríamos de frisar que pautados na perspectiva do currículo como criação cotidiana foi possível apresentar o slackline como uma possibilidade de conteúdo da escola, pois pôde ser reinventado e ressignificado de acordo com as necessidades, anseios e desejos dos sujeitos que compõem tal cenário educativo. 


\section{REFERÊNCIAS}

BETTI, Mauro. ZULIANI, Luiz Roberto. Educação Física Escolar: Uma Proposta de Diretrizes Pedagógicas. Revista Mackenzie de Educação Física e Esporte. Ano, v. 1, 2002.

CERTEAU, Michel. A invenção do cotidiano: 1. artes de fazer. Petrópolis, RJ: Vozes, 1994.

DUDLEY, Dean A. et al. Changes in physical activity levels, lesson context, and teacher interaction during physical education in culturally and linguistically diverse Australian schools. International Journal of Behavioral Nutrition and Physical Activity, London, v. 9, p. 114, 2012.

FERRAÇO, Carlos Eduardo. Pesquisa com o cotidiano. Educação e Sociedade. jan./abr. 2007,vol. 28, n. 98, p. $73-95$.

FRANCO, L.C.P; CAVASINI R.; DARIDO S.C. Práticas corporais de aventura. In: GONZÁLEZ, F.J.; DARIDO, S.C.; OLIVEIRA, A.A.B. (Org.). Lutas, Capoeira e Práticas corporais de aventura: práticas corporais e a organização do conhecimento. Maringá: Eduem; 2014. p.101135.

GIL, Antonio Carlos. Métodos e técnicas de pesquisa social. 6. ed. Editora Atlas SA, 2008.

GINZBURG, Carlo. Sinais: raízes de um paradigma indiciário. Mitos, emblemas, sinais, São Paulo: Cia das Letras, 1989, p. 143-179. 6. GUIMARÃES, Simone S.M. et al. Educação Física no Ensino Médio e as discussões sobre Meio Ambiente: um encontro necessário. Revista Brasileira de Ciências do Esporte, v. 28, n. 3, 2007.

GONZÁLEZ REY, F. Pesquisa qualitativa e subjetividade: os processos de construção da informação. São Paulo. 2012.

GUIMARÃES, Simone S.M. et al. Educação Física no Ensino Médio e as discussões sobre Meio Ambiente: um encontro necessário. Revista Brasileira de Ciências do Esporte, v. 28, n. 3, 2007.

KANTERS, Michael et al. School sport participation under two school sport policies: comparisons by race/ethnicity, gender, and socioeconomic status. The Society of Behavioral Medicine, Milwaukee, v. 47, n. 3, p. 178-194, 2012.

MARINHO, Alcyane; DE DEUS INÁCIO, Humberto Luís. Educação Física, meio ambiente e aventura: um percurso por vias instigantes. Revista Brasileira de Ciências do Esporte, v. 28, n. 3, 2007.

MAROUN, Kalyla; VIEIRA, Valdo. Impactos ambientais positivos são possíveis nos esportes praticados em ambientes naturais. Efdesportes, Revista Digital. Buenos Aires-Ano12, n. 108, 2007.

MATURANA, Humberto. Cognição, ciência e vida cotidiana. Belo Horizonte: Ed. UFMG, 2001.

MENDES, Alessandra Melato; GOMES, Daiane Alves; BELLO, Marcel. Slackline: Análise biomecânica das posições estáticas na modalidade trickline: drop knee/foot plant/buddha. Revista Corpoconsciência, v. 18, n. 1, p. 7-22, 2015.

OLIVEIRA, Inês Barbosa. Contribuições de Boaventura de Sousa Santos para a reflexão curricular: princípios emancipatórios e currículos pensadospraticados. Revista Científica e-curriculum, v. 9, n. 2, 2012. 
RODRIGUES, L. H; DARIDO, Suraya. Educação Física escolar e Meio Ambiente: reflexões e aplicações pedagógicas. Educación Física y Deportes. 2006, 11(100): 1-6. Disponível em: < http://www.efdeportes.com/efd100/ma.htm > [2015 abr].

SANCHES NETO, L. et al. Demandas ambientais na Educação Física Escolar: perspectivas de adaptação e de transformação. Movimento: Revista da Escola de Educação Física, v. 19, n. 4, p. 309-330, 2013.

SANTOS, B. S. A crítica da razão indolente: contra o desperdício da experiência. 8 ed. São Paulo: Cortez, 2011.

SOUZA JÚNIOR, O. M.; DARIDO, Suraya. C. Dispensas das aulas de Educação Física: apontando caminhos para minimizar os efeitos da arcaica legislação. Pensar a prática, v. 12, n. 2, 2009.

TAHARA, Alexander Klein; DE SENA CAGLIARI, Mayara; DARIDO, Suraya Cristina. Celular, corrida de orientação, Educação Física Escolar: elaboração e avaliação de um material didático. Arquivos de Ciências do Esporte, v. 5, n. 1, 2017.

TAHARA, Alexander Klein; DARIDO, Suraya Cristina. Práticas corporais de aventura em aulas de educação física na escola. Conexões, v. 14, n. 2, p. 113-136, 2016.

TRISTÃO, Martha. Tecendo os fios da educação ambiental: o subjetivo e o coletivo, o pensado e o vivido. Educação e Pesquisa, v. 31, n. 2, p. 251-264, 2005.

VAGO, Tarciso Mauro. Pensar a Educação Física na escola: para uma formação cultural da infância e da juventude. In Cadernos de Formação RBCE, p. 25-42, set, 2009.

ZABALZA, M. A. Diários de Aula: um instrumento de pesquisa e desenvolvimento profissional. Porto Alegre: Artmed, 2004. 